\title{
Avaliação do Efeito da Síndrome Metabólica Sobre a Função Erétil e Níveis de Testosterona em Homens com Mais de 40 Anos de Idade
}

\author{
Souza, V.; Thomaz, L.D.G.R.; Guilhermano, F.F.; Paludo, A.O.; Blaya, R.; \\ Rhoden, E.L.;
}

Apresentador: Vinícius de Souza

\section{Resumo}

Introdução: Síndrome metabólica (SM) é um conjunto de fatores de risco interrelacionados para o desenvolvimento de doença cardiovascular. O hipogonadismo tem sido destacado como potencial facilitador para instalação de algumas das características relacionadas à SM, sendo associado a doenças cardiovasculares e maior risco de aterogênese. Além disso, estudos diversos têm destacado uma potencial associação entre disfunção erétil (DE) e doença cardiovascular, inclusive com destaque para o papel da DE como preditor de eventos cardiovasculares isquêmicos em estudos longitudinais. A SM, como fator de risco para doenças cardiovasculares, deve ser considerada uma condição que pode, potencialmente, ter efeitos negativos na função sexual masculina. A relação dos andrógenos na função sexual masculina está consistentemente estabelecida, porém a relação dos andrógenos e da DE com a Síndrome metabólica carece de evidências mais definitivas. Este trabalho tem como objetivo estudar a associação entre função erétil, perfil androgênico e os parâmetros de Síndrome Metabólica em homens com idade igual ou superior a 40 anos atendidos em ambulatório de atendimento médico. Métodos: oitenta e sete homens, com idade entre 43 e 83 anos, foram incluídos em estudo transversal, multicêntrico, em que foram coletados dados demográficos, informações clínicas, informações comportamentais, medidas antropométricas e exames laboratoriais no Ambulatório de Urologia da Santa Casa de Misericórdia de Porto Alegre e no Posto de Saúde Vila Santa Izabel (Viamão - RS). Os pacientes responderam, também, questionários avaliando a função erétil (IIEF). A análise estatística foi realizada utilizando o programa SPSS e considerando-se um valor de $\mathrm{p}<, 0,05$ como estatisticamente significativo. Foram considerados critérios de exclusão: presença de cardiomiopatia ou insuficiência cardíaca, insuficiência renal (pela história clínica ou creatinina sérica $>1,5 \mathrm{mg} / \mathrm{dl}$ ), doença neoplásica conhecida, prévia ou atual, doença hepática, cirurgia pélvica ou ortopédica de grande porte prévia, tratamento atual ou prévio para $\mathrm{DE}$, doença psiquiátrica diagnosticada ou sugerida na avaliação, diagnóstico prévio de Diabete Melito.

\section{Referência:}

Souza, V.; Thomaz, L.D.G.R.; Guilhermano, F.F.; Paludo, A.O.; Blaya, R.; Rhoden, E.L.;. Avaliação do Efeito da Síndrome Metabólica Sobre a Função Erétil e Níveis de Testosterona em Homens com Mais de 40 Anos de Idade. In: II Congresso Brasileiro de Medicina Hospitalar - II CBMH [= Blucher Medical Proceedings, vol.1, num.5] São Paulo: Editora Blucher, 2014. p.94

DOI 10.5151/medpro-II-cbmh-093 